\title{
A re-evaluation of the Italian historical geomagnetic catalogue: implications for paleomagnetic dating at active Italian volcanoes
}

\author{
F. D'Ajello Caracciolo, A. Pignatelli, F. Speranza, and A. Meloni \\ Istituto Nazionale di Geofisica e Vulcanologia, Via di Vigna Murata 605, 00143 Roma, Italy \\ Received: 24 November 2010 - Published in Solid Earth Discuss.: 18 January 2011 \\ Revised: 28 April 2011 - Accepted: 6 May 2011 - Published: 9 June 2011
}

\begin{abstract}
Paleomagnetism is proving to represent one of the most powerful dating tools of volcanics emplaced in Italy during the last few centuries/millennia. This method requires that valuable proxies of the local geomagnetic field (paleo)secular variation $((\mathrm{P}) \mathrm{SV})$ are available. To this end, we re-evaluate the whole Italian geomagnetic directional dataset, consisting of 833 and 696 declination and inclination measurements, respectively, carried out since $1640 \mathrm{AD}$ at several localities. All directions were relocated via the virtual geomagnetic pole method to Stromboli $\left(38.8^{\circ} \mathrm{N}, 15.2^{\circ} \mathrm{E}\right)$, the rough centre of the active Italian volcanoes. For declinationonly measurements, missing inclinations were derived (always by pole method) by French data (for period 16701789 ), and by nearby Italian sites/years (for periods 16401657 and 1790-1962). Using post-1825 declination values, we obtain a $0.46 \pm 0.19^{\circ} \mathrm{yr}^{-1}$ westward drift of the geomagnetic field for Italy. The original observation years were modified, considering such drift value, to derive at a driftcorrected relocated dataset. Both datasets were found to be in substantial agreement with directions derived from the field models by Jackson et al. (2000) and Pavon-Carrasco et al. (2009). However, the drift-corrected dataset minimizes the differences between the Italian data and both field models, and eliminates a persistent $1.6^{\circ}$ shift of 1933-1962 declination values from Castellaccio with respect to other nearly coeval Italian data. The relocated datasets were used to calculate two post-1640 Italian SV curves, with mean directions calculated every 30 and 10 years before and after 1790, respectively. The curve comparison suggests that both available field models yield the best available SV curve to perform paleomagnetic dating of $1600-1800 \mathrm{AD}$ Italian volcanics,
\end{abstract}

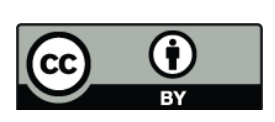

Correspondence to:

F. D'Ajello Caracciolo

(francesca.caracciolo@ingv.it) while the Italian drift-corrected curve is probably preferable for the 19th century. For the 20th century, the global model by Jackson et al. (2000) yields more accurate inclination values, while the declinations from our drift-corrected curve seem to better represent the local field evolution, at least for the first half of the century.

\section{Introduction}

During the last years there has been an increased use of paleomagnetism to provide accurate emplacement ages of products erupted by the active Italian volcanoes during the last millennia (e.g. Hoye, 1981; Rolph and Shaw, 1986; Tanguy et al., 1985, 2003; Carracedo et al., 1993; Incoronato et al., 2002; Lanza and Zanella, 2003; Speranza et al., 2004, 2006, 2008; Vezzoli et al., 2009). The paleomagnetic directions retrieved from loosely-dated volcanic rocks are compared to an independently obtained reference curve of the (paleo)secular variation $((\mathrm{P}) \mathrm{SV})$ of the geomagnetic field. This "paleomagnetic dating" method represents, in principle, the most powerful dating tool for recent (i.e., up to few ka) volcanics, where soils (datable by ${ }^{14} \mathrm{C}$ methods) hardly develop if the eruption rate is high, and $\mathrm{K} / \mathrm{Ar}$ and $\mathrm{Ar} / \mathrm{Ar}$ dates are often defined with an accuracy comparable to the absolute age values.

Clearly, a well-defined PSV reference curve is a crucial pre-requisite to efficiently use the paleomagnetic dating method. Due to the existence of non-dipolar components of the geomagnetic field, PSV curves have a regional validity, implying that Italian volcanics can be paleomagnetically dated using exclusively European and circumMediterranean PSV data, traditionally relocated to given Italian volcanoes via virtual geomagnetic pole method (Noel and Batt, 1990). Several archeomagnetic datasets and stacked

Published by Copernicus Publications on behalf of the European Geosciences Union. 


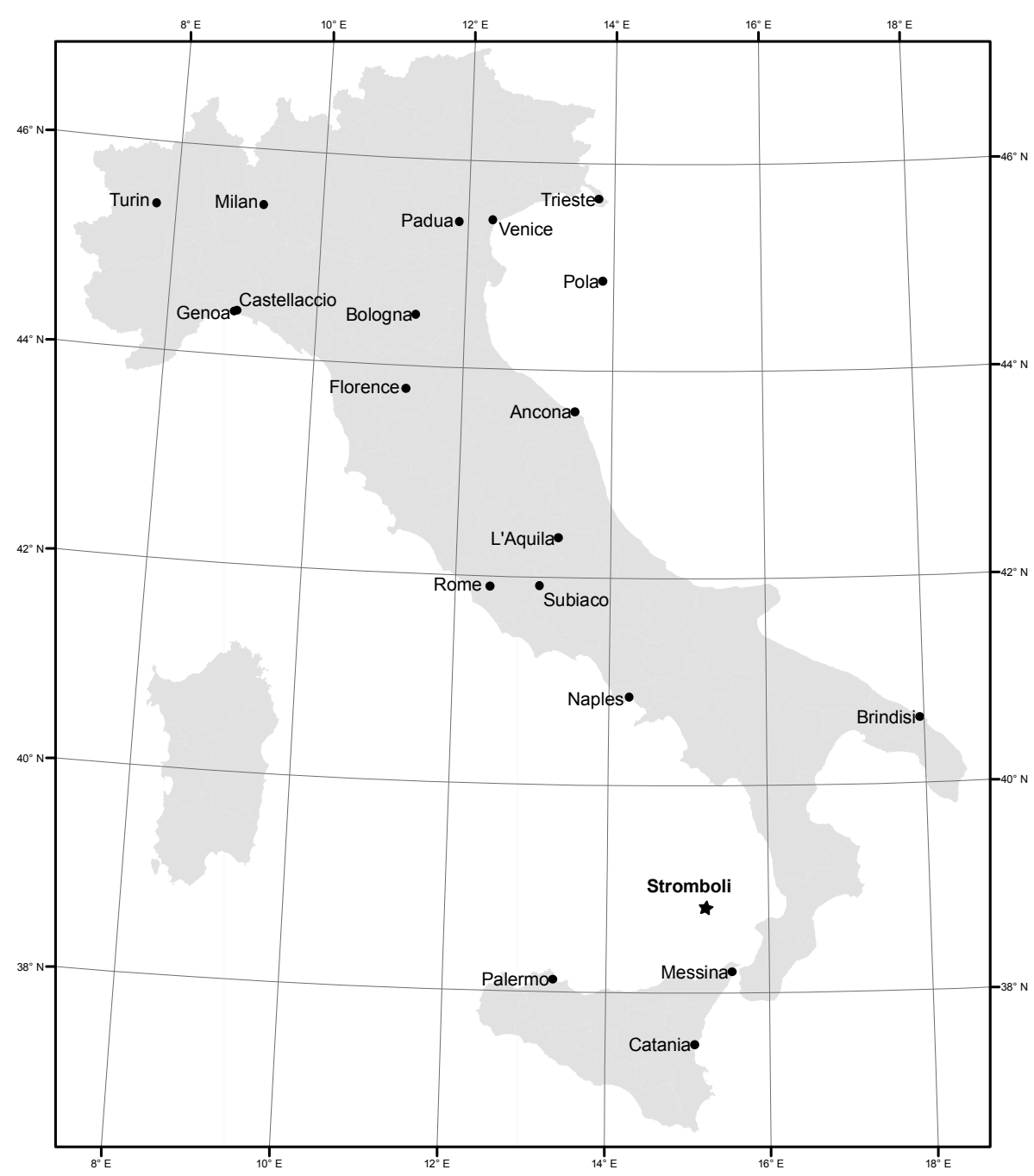

Fig. 1. The 19 localities of Italy where declination/inclination time series were gathered since 1640 (Cafarella et al., 1992; data are listed in Database S1, see Supplement). Stromboli is the site to which all geomagnetic directions were relocated.

lacustrine paleomagnetic records from several European localities have provided a valuable PSV record for Italy from ca. $10000 \mathrm{yr}$ BP to the XVII century AD (see references and discussion in Speranza et al., 2008).

However, Lanza et al. (2005) have demonstrated that the relocation via the pole method of geomagnetic directions from Chambon-La-Forêt $\left(48.02^{\circ} \mathrm{N}, 2.27^{\circ} \mathrm{E}\right.$, France), to L'Aquila $\left(42.38^{\circ} \mathrm{N}, 13.32^{\circ} \mathrm{E}\right.$, Italy) introduces errors of ca. $2^{\circ}$ (on average), due to the non-completely dipolar nature of the geomagnetic field. To overcome relocation errors, Pavon-Carrasco et al. (2009) have recently produced a regional model for the geomagnetic field in Europe for the last 3000 years (up to $1900 \mathrm{AD}$ ) using spherical caps harmonics for the spatial representation of the field. However, the Pavon-Carrasco et al. (2009) method is not exactly a pole relocation method, but it is close to it, when the low spherical cap harmonic expansion (up to spherical harmonic 2) is considered.
The SV reference curve of the last four centuries relies on direct measurements of the Earth's magnetic field. A wealth of direct geomagnetic observations gathered in several Italian localities (Fig. 1) has been reported in the Italian historical geomagnetic catalogue (Cafarella et al., 1992). Unfortunately, apart from the complete declination/inclination measurement done in 1640 by Kircher in Rome, only declination values were gathered in Italy before 1805 . Similarly, the 1933-1959 record solely relies on declination measurements from Castellaccio, near Genoa.

The lack of Italian inclination values for several decades within the last four centuries hampered the realization of a SV curve entirely made from direct geomagnetic observations from Italy, because the relocation method requires couples of declination/inclination values. Consequently, paleomagnetic dating of volcanics erupted in Italy during the last four centuries has been routinely done by relocating direct observations from France (Alexandrescu et al., 1996), or 
using the historical database and global model by Jackson et al. (2000), which, however, considers only 101 Italian data (from L'Aquila, Castellaccio, Naples, and Pola, Fig. 1) of 1900-1980 as input directions. The regional model of PavonCarrasco et al. (2009), should, in principle, take advantage of the whole Italian database of Cafarella et al. (1992), but, in fact, it seems to mix up data from Italy and from the model of Jackson et al. (2000). Data referred to Italy in Fig. 3 of Pavon-Carrasco et al. (2009) represent the Italian directional data synthesized by Lanza et al. (2005) and relocated via the pole method to Viterbo (Lat. $42.45^{\circ} \mathrm{N}$, Long. $12.03^{\circ} \mathrm{E}$ ). Yet data reported by Lanza et al. (2005) for 1600-1790 are systematically calculated from the model of Jackson et al. (2000), except the 1640 Rome measurement of Kircher.

Another controversial issue is whether to consider or not the westward drift of the geomagnetic field, when using data relocation via pole method. In fact, the average $0.38^{\circ} \mathrm{yr}^{-1}$ westward drift of the geomagnetic field for the last two millennia proposed by Merrill et al. (1996) implies that relocating observations from France or other European countries to Italy would introduce an age error of some decades for similar trends in geomagnetic elements. The first problem is that several westward drift values have been proposed for Europe relative to the last four centuries (from $0.18^{\circ} \mathrm{yr}^{-1}$ to $0.61^{\circ} \mathrm{yr}^{-1}$; Langel, 1987; Barraclough and Malin, 1999). Second, when performing paleomagnetic dating, some paleomagnetists have appropriately considered the westward drift for SV data relocation (Speranza et al., 2004, 2005, 2008), while others have decided to neglect it (Tanguy et al., 2003; Arrighi et al., 2004, 2005; Lanza et al., 2005).

In this paper, we use all available geomagnetic directional measurements which were done in Italy (as reported in the database of Cafarella et al., 1992), and verify their mutual consistency by relocating them via the pole method to a unique locality (Stromboli, $38.8^{\circ} \mathrm{N}, 15.2^{\circ} \mathrm{E}$ ). The incomplete data necessary for pole conversion (mostly inclination values) were derived by neighbouring Italian localities or years (for the periods 1640-1657 and 1790-1962), and by coeval French observations reported by Alexandrescu et al. (1996) (for the period 1670-1789). We find a $0.46 \pm 0.19^{\circ} \mathrm{yr}^{-1}$ westward drift for the last two centuries and show that westward drift should be definitely considered when relocating via pole historical observations from Italy. After comparing the Italian SV curve derived by us to the directions predicted for Stromboli by the Jackson et al. (2000) and Pavon-Carrasco et al. (2009) models, we find that a combination of the three SV curves likely represents the best proxy for the local field evolution during the last four centuries.

\section{The Italian historical geomagnetic dataset}

The Italian geomagnetic record (as reported by Cafarella et al., 1992) predominantly consists of declination time series carried out at 19 Italian localities (in Fig. 1, all directions are listed in the Database S1, see Supplement). Some declination-only time series come from the geomagnetic observatories of Pola (formerly Austro-Hungarian Empire, 1881-1922) and Castellaccio (1933-1962). Further 383 declination/inclination couples were gathered at other scattered localities from peninsular Italy, Sardinia, Sicily and minor islands.

Concerning data from 1960 to 2008 (last available datum), we refer to the directions measured at L'Aquila, main Italian geomagnetic observatory (I.N.G.V., 2008). As a whole, our dataset consists of 833/696 declination/inclination values, coming by $57 \%$ of sites located in northern Italy (i.e., north of Rome).

\section{Data relocation to a common site and evaluation of an Italian SV curve}

The time series from the 19 localities of Fig. 1 were relocated via the pole method (Noel and Batt, 1990) to the common site of Stromboli $\left(38.8^{\circ} \mathrm{N}, 15.2^{\circ} \mathrm{E}\right)$, selected as the rough centre of the active volcanoes of southern Italy (i.e., from Vesuvius to Pantelleria) where paleomagnetic dating has been used so far. The equations used to perform the relocated inclination $I_{\mathrm{r}}$ and declination $D_{\mathrm{r}}$ at the chosen reference site are the following:

$$
\begin{aligned}
& I_{\mathrm{r}}=\tan ^{-1}\left(\frac{2}{\tan (c)}\right) \\
& D_{\mathrm{r}}=\sin ^{-1}\left(\frac{\sin \beta \cos \lambda_{\mathrm{p}}}{\sin (c)}\right)
\end{aligned}
$$

where $c$ is the geomagnetic colatitude of the reference site and can be computed by:

$$
c=\tan ^{-1} \sqrt{\left\{\frac{1}{\left[\sin \lambda_{\mathrm{p}} \sin \lambda_{\mathrm{r}}+\cos \lambda_{\mathrm{p}} \cos \lambda_{\mathrm{r}} \cos \left(\Phi_{\mathrm{p}}-\Phi_{\mathrm{r}}\right)\right]^{2}}-1\right\}}
$$

and where $\lambda_{\mathrm{r}}$ and $\Phi_{\mathrm{r}}$ are the latitude and longitude of the reference site. $\beta$ is given by:

$\beta=\Phi_{\mathrm{r}}-\Phi_{\mathrm{p}}+\pi$

and where $\lambda_{\mathrm{p}}$ and $\Phi_{\mathrm{p}}$ can be computed, with a mathematical procedure, starting from the measured values of inclination $I_{\mathrm{M}}$ and declination $D_{\mathrm{M}}$ as stated by Irving (1964),

This choice would allow the comparison of the SV curve, derived by us, with few or no corrections to paleomagnetic data gathered from active Italian volcanoes.

In order to use the whole Italian dataset, lacking inclinations were derived (always by the pole method) by as nearby as possible sites/years. Declination values from 1640 to 1657 were relocated using the inclination $\left(66^{\circ}\right)$ gathered in 1640 by Kircher in Rome. Conversely, declinations from 1670 to 1789 were relocated using coeval directions from France 

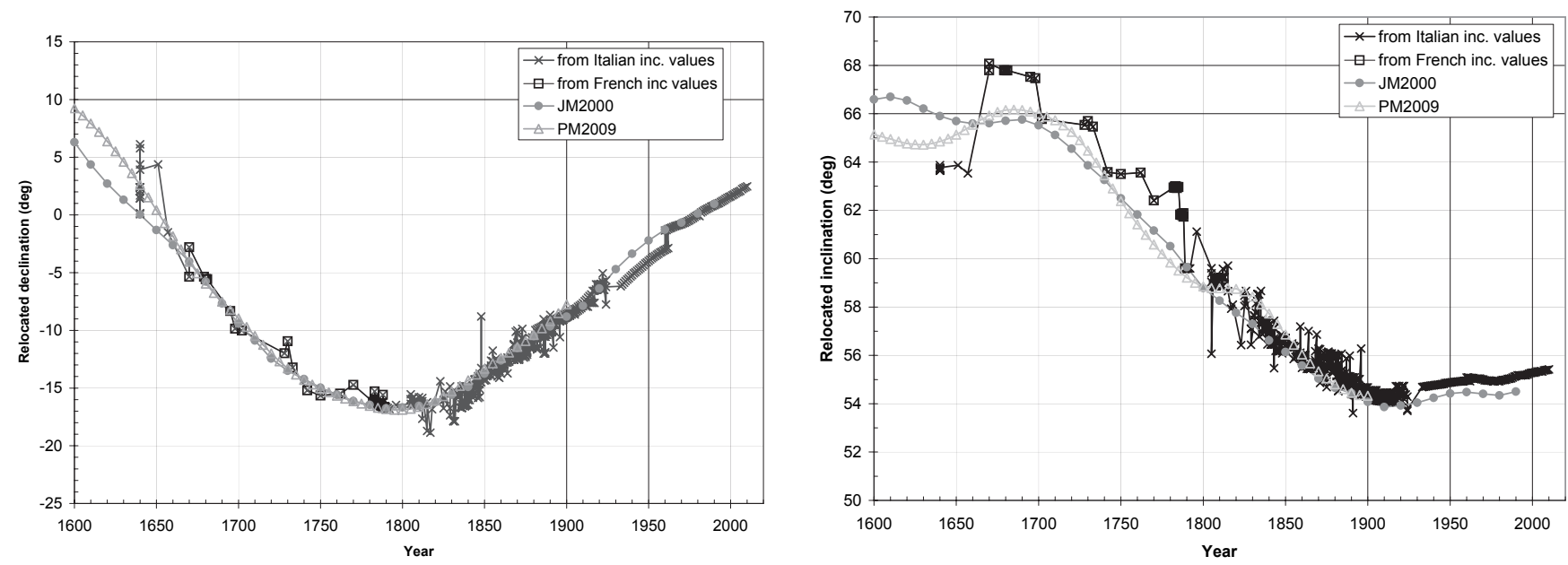

Fig. 2. Italian geomagnetic observations relocated to Stromboli $\left(38.8^{\circ} \mathrm{N}, 15.2^{\circ} \mathrm{E}\right)$ via the pole method, along with $1600-1990$ (and $1600-$ 1900) directions derived for Stromboli from JM2000 (and PM2009) models. Italian declinations gathered between 1670 and 1789 were relocated using coeval French geomagnetic observations (Alexandrescu et al., 1996).

(Alexandrescu et al., 1996). Since 1790, missing inclinations were obtained by close Italian localities, or by the direction measured at the same locality a few (up to 16) years before/after. Lacking inclinations from Castellaccio were derived by the 1929 direction from Alessandria $\left(44.92^{\circ} \mathrm{N}\right.$, $8.62^{\circ} \mathrm{E}$ ), and the 1960-1962 directions from L'Aquila. Negligible errors are introduced when considering inclination values measured in nearby years of the 19th-20th centuries, as inclination values (as calculated from Jackson et al., 2000) have changed by solely $\sim 0.03^{\circ}$ and $0.01^{\circ} \mathrm{yr}^{-1}$ during 1830 1910 and 1910-1990, respectively. All Italian data relocated to Stromboli are listed in Database S2 (see Supplement).

Similar to all other European datasets, the relocated declinations show a trend of decreasing values after 1640, with a declination minimum of ca. $-17^{\circ}$ around 1800 , followed by a rough linear value increase up to the present (Fig. 2). The Castellaccio declination series is visibly shifted by $1.6^{\circ}$ with respect to the other data. In principle, the Castellaccio declination shift might arise from several possible sources, such as the westward drift of the geomagnetic field, errors introduced by data relocation via the pole method, local (due to the Castellaccio fortress walls) and/or regional magnetic anomalies. Considering the latter source, we note that the area of Castellaccio is characterised by a negative magnetic anomaly of less than $|100| \mathrm{nT}$ at gound level (Chiappini et al., 2000). The spatial resolution of the Chiappini et al. (2000) magnetic anomaly map is about $10 \times 10 \mathrm{~km}$, which indeed gives room for strong local anomalies at Castellaccio. However, Zanella (1998) has calculated that even an anomaly as strong as the $1650 \mathrm{nT}$ observed at Pantelleria (Strait of Sicily) cannot yield a field deflection exceeding $1^{\circ}$. Thus, it is unlikely that the $1.6^{\circ}$ declination shift observed at Castellaccio is entirely due to local magnetic anomalies.
Relocated inclination data increase from $\sim 64^{\circ}$ to $\sim 68^{\circ}$ from 1640 to 1670 , then decrease to a minimum of $54^{\circ}$ $55^{\circ}$ in 1910-1920, and slowly increase afterwards. In Fig. 2 we have also plotted the geomagnetic directions expected at Stromboli considering the historical record database and global model by Jackson et al. (2000), hereinafter referred to as JM2000, and the regional European model by PavonCarrasco et al. (2009), hereinafter referred to as PM2009. Declination values derived from Italian data are, at first glance, consistent with declinations calculated from JM2000 and PM2009. The several Italian declination values available for $1640\left(0.1-6.1^{\circ}\right)$ are roughly consistent with the declination derived from PM2009 $\left(2.6^{\circ}\right)$, but slightly greater than the null declination predicted by the JM2000 model.

Conversely, systematic differences exist when the inclination dataset is considered. The inclination measured by Kircher at Rome in 1640 is ca. $2^{\circ}$ and $1^{\circ}$ smaller than that predicted by JM2000 and PM2009, respectively, whereas all remaining Italian-derived inclination values of 1670-1790 are systematically greater by $1^{\circ}-2^{\circ}$ than coeval values derived from JM2000 and PM2009. This significant mismatch occurs in the period for which French directions were used to relocate Italian-only declinations. The 1810-1860 inclinations derived from PM2009 are greater by ca. $1^{\circ}$ than both Italian data and inclinations from JM2000. A small $\left(\sim 0.5^{\circ}\right)$ but systematic difference of Italian data, with respect to JM2000 inclinations, exists even for 1960-1990, a period for which Italian inclinations are relocated from the directions carefully measured at the L'Aquila geomagnetic observatory.

The directional values shown in Fig. 2 were used to derive a mean Italian SV curve for 1640-2010. Declination data from Castellaccio were arbitrarily increased by $1.6^{\circ}$, to annul the mismatch evident in Fig. 2. We used a nine-degree 
Table 1. Mean directions calculated by means of a 9th polinomyal degree interpolation after having relocated all Italian data to Stromboli $\left(38.8^{\circ} \mathrm{N}, 15.2^{\circ} \mathrm{E}\right)$ via the pole method, and having systematically increased declination values of the Castellaccio series (years 1933-1962) by $1.6^{\circ}$ (see text).

\begin{tabular}{rrlll}
\hline Year & $D\left(^{\circ}\right)$ & $\Delta D\left(^{\circ}\right)$ & $I\left(^{\circ}\right)$ & $\Delta I\left(^{\circ}\right)$ \\
\hline 1640 & 2.61 & 1.32 & 63.63 & 0.86 \\
1670 & -3.08 & 1.38 & 66.74 & 0.9 \\
1700 & -9.51 & 1.37 & 66.72 & 0.89 \\
1730 & -12.7 & 1.38 & 65.09 & 0.9 \\
1760 & -14.6 & 1.33 & 63.48 & 0.87 \\
1790 & -16.38 & 1.3 & 61.12 & 0.84 \\
1800 & -16.74 & 1.29 & 60.18 & 0.84 \\
1810 & -16.86 & 1.29 & 59.23 & 0.84 \\
1820 & -16.68 & 1.28 & 58.34 & 0.84 \\
1830 & -16.19 & 1.28 & 57.56 & 0.83 \\
1840 & -15.4 & 1.28 & 56.92 & 0.83 \\
1850 & -14.38 & 1.28 & 56.4 & 0.83 \\
1860 & -13.22 & 1.28 & 55.98 & 0.83 \\
1870 & -12.01 & 1.28 & 55.62 & 0.83 \\
1880 & -10.85 & 1.28 & 55.27 & 0.83 \\
1890 & -9.77 & 1.28 & 54.91 & 0.83 \\
1900 & -8.77 & 1.28 & 54.56 & 0.83 \\
1910 & -7.75 & 1.28 & 54.29 & 0.84 \\
1920 & -6.6 & 1.29 & 54.2 & 0.84 \\
1930 & -5.19 & 1.29 & 54.38 & 0.84 \\
1940 & -3.55 & & 54.76 & \\
1950 & -2.34 & & 54.88 & \\
1960 & -1.36 & & 54.95 & \\
1970 & -0.79 & & 55.08 & \\
1980 & -0.01 & & 54.93 & \\
1990 & 0.84 & & 55.14 & \\
2000 & 1.62 & & 55.28 & \\
2010 & 2.48 & & 55.42 & \\
\hline & & & &
\end{tabular}

polynomial best-fit curve (nonlinear least square minimization) to adequately represent data evolution. By means of the polynomial coefficients found, we have calculated mean directions every 30 and 10 years before and after 1790, respectively (Fig. 3). The errors associated to the calculated data were computed using the $90 \%$ confidence interval of the predicted polynomial values (Table 1). Confidence intervals were calculated by the QR decomposition of the Jacobian technique. We also tried to use the same fitting technique adding the other 383 declination/inclination couples from scattered Italian localities, but found $>10 \%$ higher errors, and consequently decided to eliminate the 383 value couples from further consideration. Considering errors, the oldest track of our SV curve is better resolved than the coeval PM2009 curve, yelding $1.71^{\circ}$ error for the XVI-XVII centuries. Conversely no errors are available from the JM2000 model.

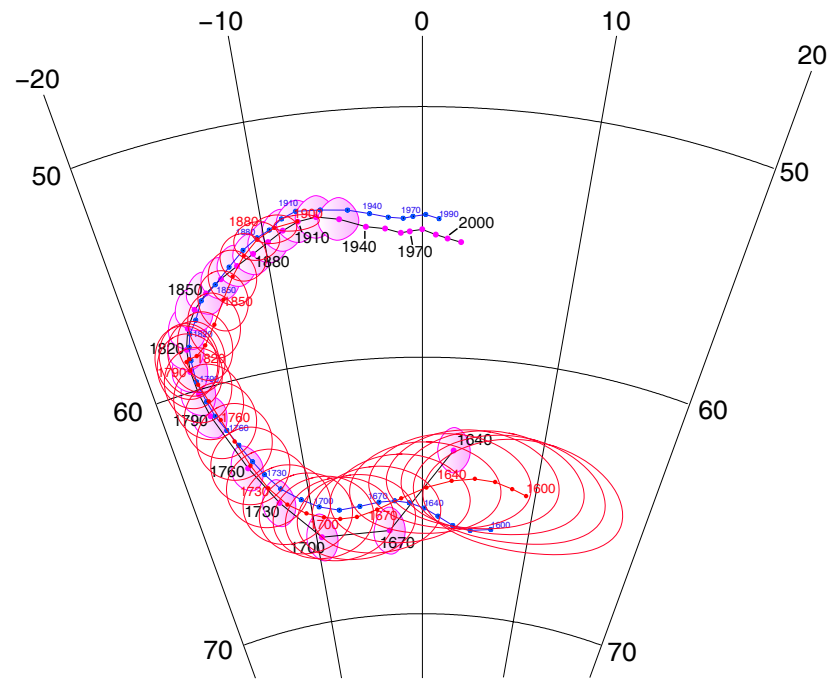

Fig. 3. Equal-area projection (lower hemisphere) of post-1640 mean Italian SV directions, calculated by means of a 9th polinomyal degree interpolation, from data of Fig. 2, and post-1600 directions, derived for Stromboli from JM2000 (blue dots and lines) and PM2009 (red dots and lines) models. Numbers adjacent to directions indicate ages $\mathrm{AD}$. Ellipses indicate $\Delta D / \Delta I$ values of the mean Italian directions as listed in Table 1.

\section{Westward drift of the geomagnetic field}

It has long been known that geomagnetic field elements directly measured during the last four centuries have undergone a detectable westward drift. Secular variation of the Earth's magnetic field is a global phenomenon, but shows some regional peculiarities. Westward drift in particular is an observable feature with evident regional peculiarities. It manifests in the Atlantic Ocean and in the Mediterranean Sea, while it is almost absent in the Pacific Ocean. Therefore, the westward drift is mostly due to non-dipolar Earth's core contributions. The largest changes in the direction of the Earth's magnetic field are associated with the non-dipole part of the field. Bullard et al. (1950) adopted at a global scale a $0.18^{\circ} \mathrm{yr}^{-1}$ drift value (see also, Langel, 1987), while Barraclough and Malin (1999) have calculated a $0.61 \pm 0.08^{\circ} \mathrm{yr}^{-1}$ value considering the declination minimum recorded between 1750 and 1860 at different European sites. By considering also archeomagnetic data, Merrill et al. (1996) have proposed a global $0.38 \pm 0.07^{\circ} \mathrm{yr}^{-1}$ value for the last 2000 years. The westward drift has been routinely neglected, when relocating via pole method direct geomagnetic observations or archeomagnetic data to active Italian volcanoes (with the exception of paleomagnetic studies on Stromboli carried out by Speranza et al., 2004, 2008). Recently, Speranza et al. (2005) and Arrighi et al. (2005) have specifically concentrated on the necessity (or not) to add the westward drift correction to data relocation. 


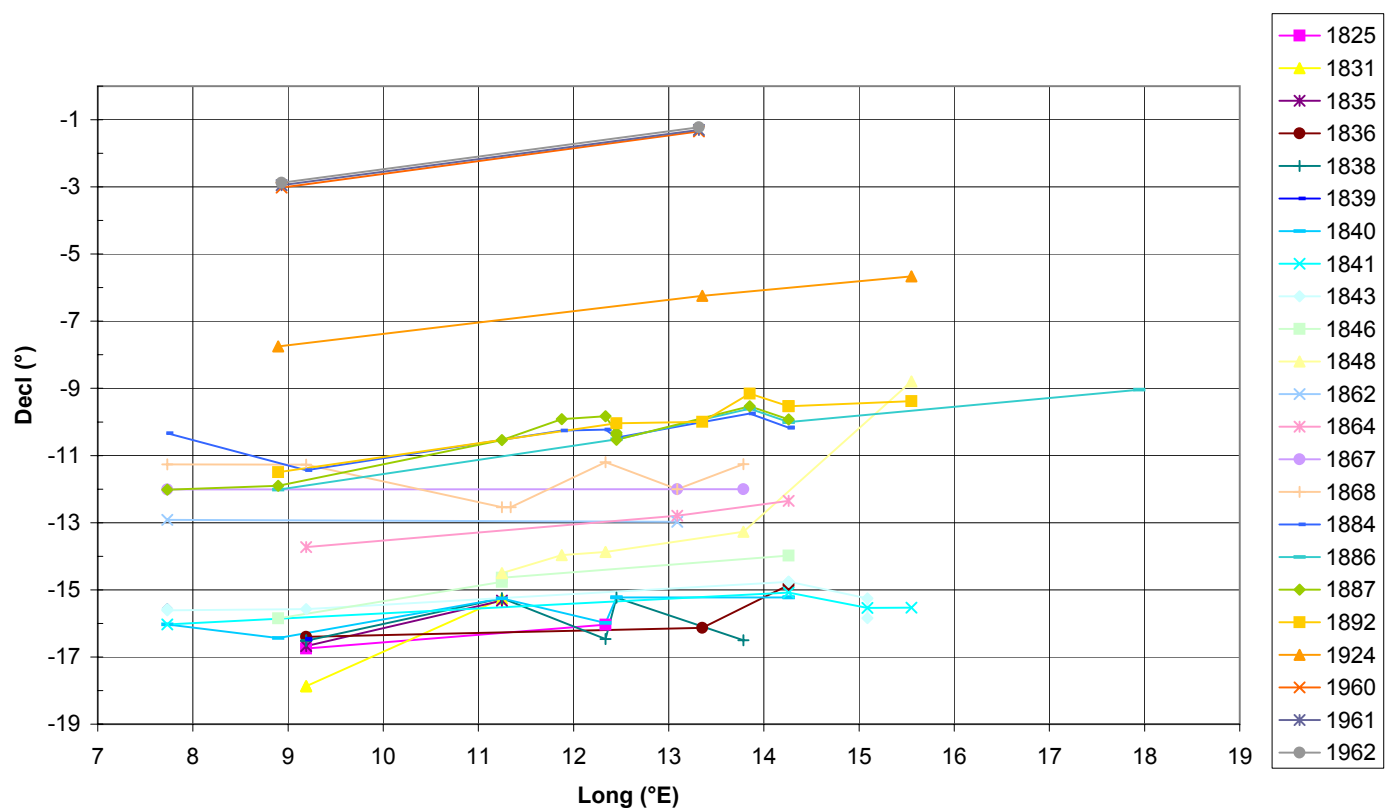

Fig. 4. Declination values measured during the same year at different Italian sites (since 1825 and relocated to Stromboli via the pole method) versus site longitude values.

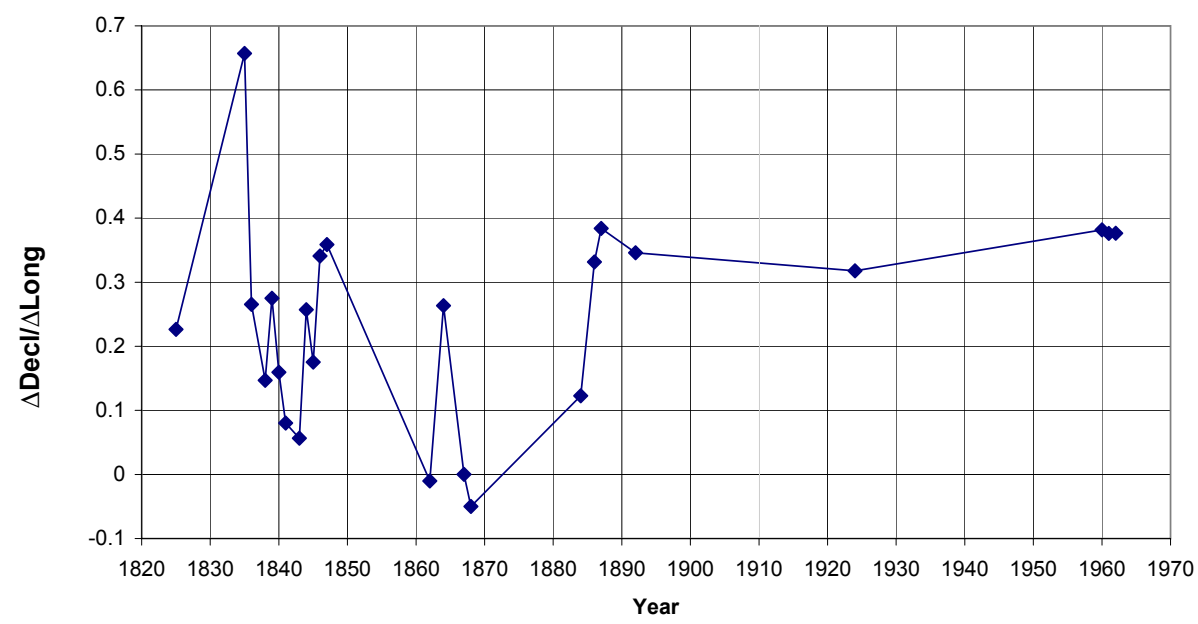

Fig. 5. $\Delta$ decl/ $\Delta$ long values as derived from data of Fig. 4 versus corresponding years of observation. Significantly greater $(>1.2)$ values for years 1831 and 1848 were omitted.

The wealth of declination values from different Italian localities reported by the catalogue of Cafarella et al. (1992) offers the opportunity to better evaluate the westward drift occurring in Italy (roughly between $7^{\circ}$ and $18^{\circ} \mathrm{E}$ longitude) during the last few centuries. In Fig. 4 we show the declination values measured in the same years at two (or more) sites from 1825 to 1962 (before 1825 no declinations from multiple sites are available, with the exception of year 1640). The slopes of the best-fit lines considered for each year define $\Delta \mathrm{decl} / \Delta$ long values varying between 0.66 and -0.20 (Fig. 5). The $\Delta \mathrm{decl} / \Delta$ long average is $0.22 \pm 0.12$, after excluding the very high values of years 1831 and $1848(>1.2$, whereas most of the data are $<0.4$ ).

Age correction due to westward drift can be evaluated as it follows. The declination value is a function dependent on the longitude of a site and the year of the measurement. So we can write:

$D=D(l, t)$

where $D=$ declination $l=$ longitude and $t=$ time. The value of the declination can be approximated, by means of Taylor formula, as follows: 

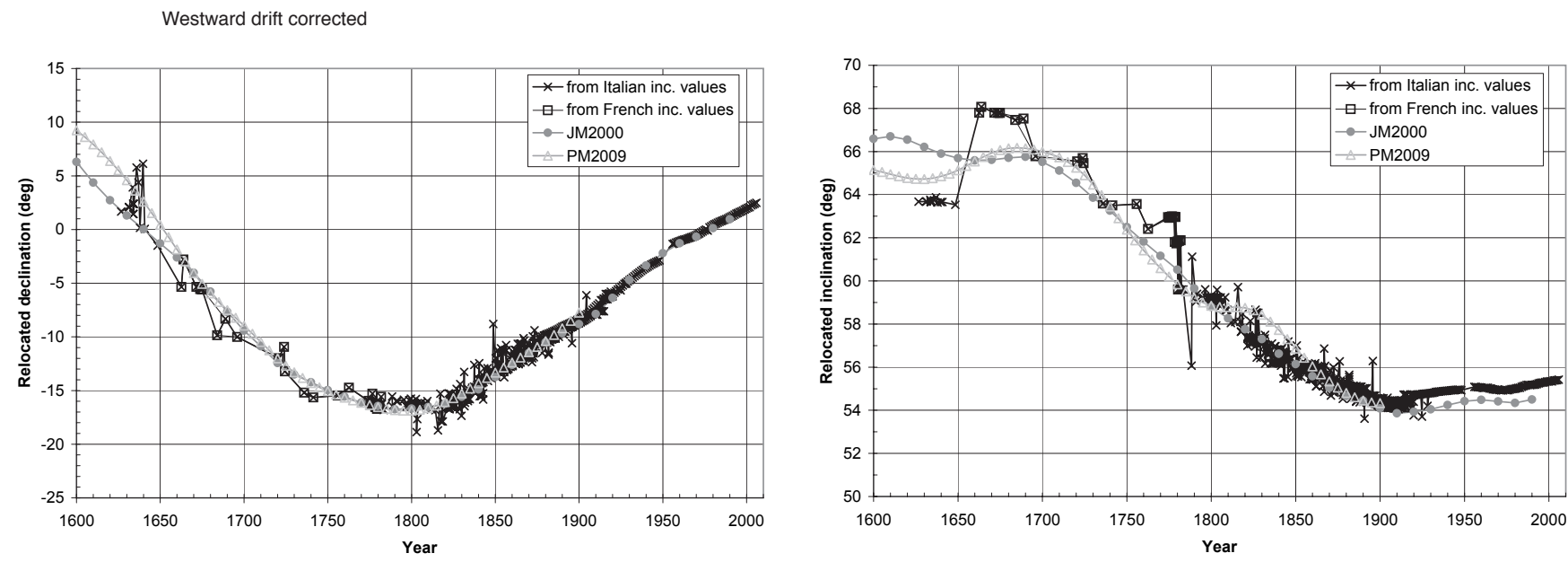

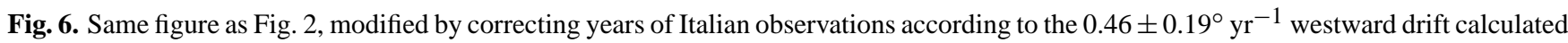
for Italian data.

$$
\begin{aligned}
D(l, t) & =D\left(l_{0}, t_{0}\right)+\left(\frac{\partial}{\partial t} D(l, t)\right)_{l_{0}}\left(t-t_{0}\right) \\
& +\left(\frac{\partial}{\partial l} D(l, t)\right)_{t_{0}}\left(l-l_{0}\right)
\end{aligned}
$$

This formula can be used to compute the year $t$ of a site with declination $D$. In fact, if we have, in the chosen site, a reference curve, we can estimate the value of $t_{0}$ corresponding to the year when the declination is the same as the measured one. In this case the Eq. (10) becomes:

$$
\left(\frac{\partial}{\partial t} D(l, t)\right)_{l_{0}}\left(t-t_{0}\right)+\left(\frac{\partial}{\partial l} D(l, t)\right)_{t_{0}}\left(l-l_{0}\right)=0
$$

So the year $t$ can be computed by:

$t=t_{0}-\frac{\left(\frac{\partial}{\partial l} D(l, t)\right)_{t_{0}}}{\left(\frac{\partial}{\partial t} D(l, t)\right)_{l_{0}}}\left(l-l_{0}\right)$

If we assume slow variation of declination with the two parameters in a period, the ratio between the two partial derivatives can be approximated by their mean values:

$t=t_{0}-\frac{<\left(\frac{\partial}{\partial l} D(l, t)\right)_{t_{0}}>}{<\left(\frac{\partial}{\partial t} D(l, t)\right)_{l_{0}}>}\left(l-l_{0}\right)$

The westward drift is defined as:

$w_{\mathrm{d}}=\frac{<\left(\frac{\partial}{\partial l} D(l, t)\right)_{t_{0}}>}{<\left(\frac{\partial}{\partial t} D(l, t)\right)_{l_{0}}>}$

And so the age correction due to the westward drift can be computed by:

$t=t_{0}-w_{\mathrm{d}}\left(l-l_{0}\right)$

The westward drift ( $\Delta$ long/ $\Delta \mathrm{yr}$ ) of declination is the ratio between the declination variation vs. time $(\Delta \mathrm{decl} / \Delta \mathrm{yr})$ between 1825 and 1962 (we consider the $0.101 \pm 0.003^{\circ} \mathrm{yr}^{-1}$ value calculated from 1840 to 1960 , Fig. 2), and the average $0.22 \pm 0.12 \Delta \mathrm{decl} / \Delta$ long value calculated from Fig. 5 . We eventually get a specific value of $0.46 \pm 0.19^{\circ} \mathrm{yr}^{-1}$ westward drift value for the Mediterranean region post-1825 declination values, which is statistically undistinguishable from both the $0.38 \pm 0.07^{\circ} \mathrm{yr}^{-1}$ global value calculated by Merrill et al. (1996) for the last two millennia, and the $0.61 \pm 0.08^{\circ} \mathrm{yr}^{-1}$ value calculated by Barraclough and Malin (1999) for the European declination minimum of 1750-1860.

We have modified the years of the relocated directions of Fig. 2 taking into account the $0.46 \pm 0.19^{\circ} \mathrm{yr}^{-1}$ westward drift value calculated above (Fig. 6). All relocated and westward drift-corrected data are listed in Database S3 (see Supplement). Italian declinations are again in gross agreement with those derived from the JM2000 and PM2009 models, and the discrepancy of declinations measured in Italy in 1640 with respect to declination derived from JM2000 is reduced. Surprisingly, the shift of declinations data from Castellaccio gathered at 1933-1962 (with respect to both other Italian data and JM2000, Fig. 2) is annulled. We conclude that the mismatch of declination data from Castellaccio, as evident in Fig. 2, is entirely due to the westward drift of the geomagnetic field, and no other factors (such as errors arising from data relocation via the pole method or local/crustal magnetic anomalies) are involved.

Inclination data corrected for the westward drift (Fig. 6) show a better agreement than non-corrected data of Fig. 2 with respect to JM2000 and PM2009, though inclination differences for pre- 1800 and post- 1900 years persists. A similar $1^{\circ}-2^{\circ}$ difference exists between the inclination relocated from the measurement of 1640 of Rome by Kircher, and the coeval inclinations calculated by the JM2000 and PM2009 
Table 2. Mean directions calculated by means of a 9th polinomyal degree interpolation after having relocated all Italian data to Stromboli $\left(38.8^{\circ} \mathrm{N}, 15.26 \circ \mathrm{E}\right)$ via pole method, and having corrected the observation years considering a $0.46^{\circ} \mathrm{yr}^{-1}$ westward drift (see text).

\begin{tabular}{rrrlr}
\hline Year & $D\left(^{\circ}\right)$ & $\Delta D\left(^{\circ}\right)$ & $I\left(^{\circ}\right)$ & $\Delta I\left(^{\circ}\right)$ \\
\hline 1640 & 0.92 & 1.67 & 62.59 & 1.26 \\
1670 & -5.11 & 1.21 & 67.42 & 0.92 \\
1700 & -10.33 & 1.23 & 65.93 & 0.93 \\
1730 & -13.59 & 1.22 & 64.75 & 0.93 \\
1760 & -15.08 & 1.17 & 63.15 & 0.88 \\
1790 & -16.59 & 1.14 & 60.31 & 0.86 \\
1800 & -16.84 & 1.14 & 59.3 & 0.86 \\
1810 & -16.77 & 1.13 & 58.38 & 0.86 \\
1820 & -16.33 & 1.13 & 57.61 & 0.86 \\
1830 & -15.54 & 1.13 & 56.99 & 0.86 \\
1840 & -14.47 & 1.13 & 56.51 & 0.85 \\
1850 & -13.27 & 1.13 & 56.13 & 0.86 \\
1860 & -12.12 & 1.13 & 55.79 & 0.86 \\
1870 & -11.1 & 1.13 & 55.43 & 0.86 \\
1880 & -10.25 & 1.13 & 55.06 & 0.85 \\
1890 & -9.5 & 1.13 & 54.7 & 0.86 \\
1900 & -8.59 & 1.13 & 54.44 & 0.86 \\
1910 & -7.34 & 1.14 & 54.37 & 0.86 \\
1920 & -5.83 & 1.14 & 54.5 & 0.86 \\
1930 & -5.03 & 1.28 & 54.61 & 0.97 \\
1940 & -3.55 & & 54.91 & \\
1950 & -2.55 & & 54.8 & \\
1960 & -1.09 & & 55.06 & \\
1970 & -0.53 & & 54.95 & \\
1980 & 0.4 & & 55 & \\
1990 & 1.13 & & 55.18 & \\
2000 & 1.95 & & 55.33 & \\
2005 & 2.48 & & 55.42 & \\
\hline & & & &
\end{tabular}

models. The 1640 inclination was measured by the angle of inclination, or dip, of a suspended magnet. Due to several problems, the inclination was more difficult to measure accurately than declination, so that the validity of the 1640 inclination measurement remains as uncertain.

Again, for 1810-1860 the PM2009 model predicts inclinations higher by ca. $1^{\circ}$ than both Italian inclinations and those derived from JM2000. Furthermore, the same $\sim 0.5^{\circ}$ shift with respect to JM2000 is apparent even for Italian inclinations of 1960-1990, relocated by the directions carefully measured at the L'Aquila observatory. Conversely, the 19601990 inclinations derived from JM2000 for L'Aquila are in good agreement with those effectively measured at L'Aquila in the same years (differences are always less than $0.1^{\circ}$ ). We conclude that data relocation via the pole method from L'Aquila to Stromboli (located $420 \mathrm{~km}$ apart) introduces a $\sim 0.5^{\circ}$ inclination error, at least after 1960 .

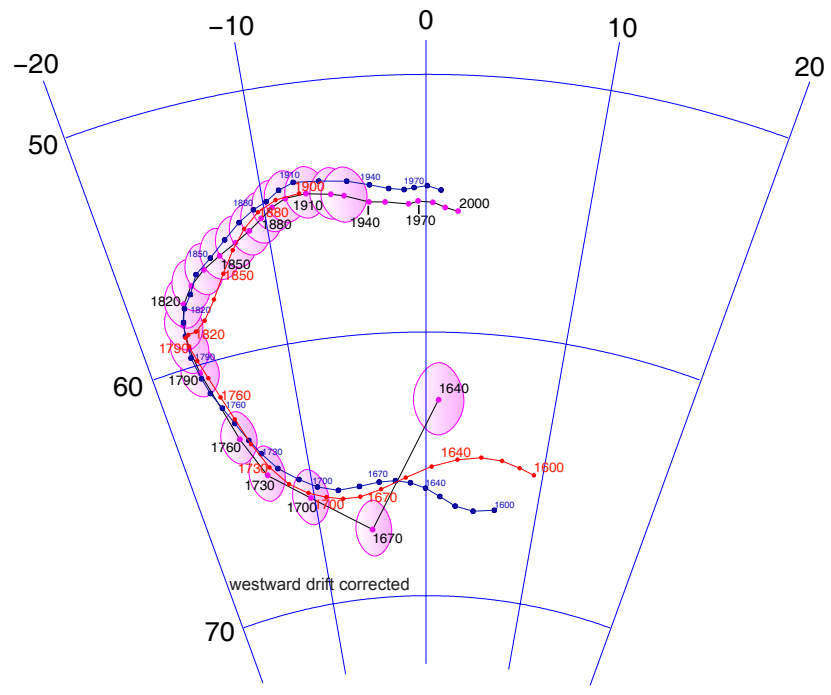

Fig. 7. Same figure and symbols as Fig. 3 but considering driftcorrected Italian data of Fig. 6. Equal area projection, lower emiphere of post-1640 mean Italian SV directions are calculated from data of Fig. 6 by means of a 9th polinomyal degree interpolation. Ellipses indicate $\Delta D / \Delta I$ values of the mean drift-corrected Italian directions as listed in Table 1. Errors of data from the PM2009 model are omitted.

Data corrected for the westward drift were used to derive an additional post-1640 Italian SV curve (Fig. 7 and Table 2), using the same method adopted for Fig. 3. Mean directions calculated every 30 and 10 years (before and after 1790, respectively) are defined with a similar precision. Drift corrected data show a greater and smaller precision on declination and inclination data, respectively, and this is likely the consequence of using declination data to calculate the westward drift value.

\section{Best SV curve(s) to perform paleomagnetic dating of volcanics erupted in Italy during the last four centuries}

The analysis of Italian data, compared to the directions predicted for Italy by the JM2000 and PM2009 models, may suggest which SV curves are best suited to perform paleomagnetic dating at active Italian volcanoes. We propose that JM2000 or PM2009 model should be adopted for the 1600 1800 period. In fact, both models do not suffer probable inclination errors introduced in the Italian curve by the use of French directions during 1670-1789, when no Italian inclination are available. For the period 1810-1860, the Italian drift-corrected data are in good agreement with directions derived from the JM2000 model (which, however, uses no Italian data in such a time window), while the PM2009 models yield inclinations values higher by ca. $1^{\circ}$. Thus, we suggest that the drift-corrected Italian curve may be preferable 
for the 19th century, as in this time span a wealth of declination/inclination values from Italy are available. Concerning the 20th century, declination values of our drift-corrected SV curve (averaging some 110 Italian declination values) seem more realistic than those derived from the JM2000 model (using a total number of 101 declination/inclination values from four localities), at least for the first half of the century (only the drift-corrected Italian curve shows a change of slope in the data time series in correspondence to the 1901 geomagnetic jerk). Conversely, a systematic $\sim 0.5^{\circ}$ bias introduced by pole relocation from L'Aquila to Stromboli implies that inclinations derived from JM2000 are better suited to perform paleomagnetic dating of volcanics erupted in Italy during the 20th century.

\section{Conclusions}

Directional (mostly declination) time series gathered from 19 Italian localities since 1640 AD Cafarella et al. (1992) were relocated to Stromboli $\left(38.8^{\circ} \mathrm{N} ; 15.2^{\circ} \mathrm{E}\right)$ via the pole method (Noel and Batt, 1990). Since data relocation requires a complete directional measurement, missing inclinations were derived (always by pole method) by French (16701789 period) and nearby Italian (1640-1657 and 1790-1962 periods) directions. A $0.46 \pm 0.19^{\circ} \mathrm{yr}^{-1}$ westward drift derived from post-1825 Italian declination values was applied to the relocated data and yielded an additional Italian driftcorrected dataset. Both datasets were compared to the directions expected at Stromboli using the datasets and models by Jackson et al. (2000) and Pavon-Carrasco et al. (2009) (both avoid errors arising from data relocation via pole method).

The westward drift correction eliminates the significant discrepancy $\left(1.6^{\circ}\right)$ of declination data from Castellaccio with respect to both other Italian declination values, and the declinations derived from the field model of Jackson et al. (2000). Drift correction also reduces the differences between the remaining Italian data and the field models. Two different Italian SV reference curves, yielding mean directions every 30 years from 1640 to 1790 , and every 10 years afterwards, were calculated from the two datasets by using a polynomial fitting technique. Our data suggest that westward drift (if properly determined for a given period) should be considered when relocating geomagnetic/archeomagnetic data via the pole method.

The comparison between the Italian SV curves derived by us and the field models by Pavon-Carrasco et al. (2009) and Jackson et al. (2000) suggests that both models probably yield the best available 1600-1800 SV curve for Italy to be used for paleomagnetic dating at active Italian volcanoes, while the drift-corrected Italian curve seems to be preferable for the 19th century. For the 20th century, the model of Jackson et al. (2000) yields the more accurate inclination values, while our SV curve suffers systematic bias arising from the pole relocation procedure. Conversely, declination values of our drift-corrected SV curve are probably more realistic, at least for the first half of the century.

\section{Supplementary material related to this article is available online at: http://www.solid-earth.net/2/65/2011/ se-2-65-2011-supplement.zip.}

Acknowledgements. We thank Lili Cafarella for discussions on the Italian historical dataset, Roberto Carluccio for his technical suggestions and the referees Monika Korte and E. Thebault for providing careful reviews of our manuscript.

Edited by: V. Lesur

\section{References}

Alexandrescu, M., Coutillot, V., and Mouel, J.-L. L.: Geomagnetic field direction in Paris since the mid-sixteenth century, Phys. Earth Planet. Int., 98, 321-360, 1996.

Arrighi, S., Rosi, M., Tanguy, J.-C., and Courtillot, V.: Recent eruptive history of Stromboli (Aeolian Islands, Italy) determined from high-accurancy archeomagnetic dating, Geophys. Res. Lett., 31, L19603, doi:10.1029/2004GL020627, 2004.

Arrighi, S., Tanguy, J.-C., Courtillot, V., and Goff, M. L.: Reply to comment by F. Speranza et al. on "Recent eruptive histoy of Stromboli (Aeolian Islands, Italy) determined from highaccurancy archeomagnetic dating", Geophys. Res. Lett., 32, L23305, doi:10.1029/2005GL023768, 2005.

Barraclough, D. and Malin, S.: A fast-moving feature of westward drift, Ann. Geophys., 42, 21-26, 1999,

http://www.ann-geophys.net/42/21/1999/.

Bullard, E., Freedman, C., Gellman, H., and Nixon, J.: The westward drift of the earth's magnetic field, Philos. T. Roy. Soc. London A, 243, 67-92, 1950.

Cafarella, A., De Santis, A., and Meloni, A.: Il catalogo geomagnetico storico italiano, Istituto Nazionale di Geofisica, Roma, Italy, 1992.

Carracedo, J., Principe, C., Rosi, M., and Soler, V.: Time correlation by paleomagnetism of the 1631 eruption of Mount Vesuvius. Volcanological and volcanic hazard implications, J. Volcanol. Geotherm. Res., 58, 203-209, 1993.

Chiappini, M., Meloni, A., Boschi, E., Faggioni, O., Beverin, N., Carmisciano, C., and Marson, L.: Shaded relief total field magnetic anomaly map of Italy and surrounding marine areas at sea level., Annali di Geofisica, 43(5), 983-989, 2000.

Hoye, G.: Archeomagnetic secular variation record of Mount Vesuvius, Nature, 291, 21-218, 1981.

Incoronato, A., Angelino, A., Romano, R., Ferrante, A., Sauna, R., Vancore, G., and Secchione, G.: Retrieving geomagnetic secular variations from lava flows: Evidence from Mounts Arso, Etna and Vesuvius (southern Italy), Geophys. J. Int., 149, 724-730, 2002.

I.N.G.V.: Risultati delle Osservazioni Magnetiche 2008, Istituto Nazionale di Geofisica e Vulcanologia, L'Aquila, Italy, 2008.

Irving, E.: Paleomagnetism and its Application to Geological and Geophysical Problems, John Wiley, New York, 1964. 
Jackson, A., Jonkers, A., and Walker, M.: Four centuries of geomagnetic secular variation from historical records, Philos. T. Roy. Soc. London A, 358, 957-990, 2000.

Langel, R.: The main field, in: Geomagnetism, Academic Press, London, 1, 249-512, 1987.

Lanza, R. and Zanella, E.: Paleomagnetic secular variation at Vulcano (Aeolian Islands) during the last $135 \mathrm{kyr}$, Earth Planet. Sc. Lett., 213, 321-336, 2003.

Lanza, R., Meloni, A., and Tema, E.: Historical measurements of the Earth's magnetic field compared with remanence directions from lava flows in Italy over the last four centuries, Phys. Earth Planet. Int., 148, 97-107, 2005.

Merrill, R., McElhinny, M., and McFadden, P.: The Magnetic Field of the Earth: Paleomagnetism, the Core, and the Deep Mantle, Elsevier, New York, 1996.

Noel, M. and Batt, C.: A method for correcting geographically separated remanence directions for the purpose of archeomagnetic dating, Geophys. J. Int., 102, 753-756, 1990.

Pavon-Carrasco, F., Osete, M., Torta, J., and Gaya-Piqué, L.: A regional archeomagnetic model for Europe for the last 3000 years, SCHA.DIF.3K: Applications to archeomagnetic dating, Geochem. Geophy. Geosy., 10, Q03013, doi:10.1029/2008GC002244, 2009.

Rolph, T. and Shaw, J.: Variations of the geomagnetic field in Sicily, Geophys. J. Int., 38, 1269-1277, 1986.

Speranza, F., Pompilio, M., and Sagnotti., L.: Paleomagnetism of spatter lavas from Stromboli volcano (Aeolian Island, Italy): Implications for the age of paroxysmal eruptions, Geophys. Res. Lett., 31, L02607, doi:10.1029/2300GL018944, 2004.
Speranza, F., Sagnotti, L., and Meloni, A.: Comment on "Recent eruptive history of Stromboli (Aeolian islands, Italy) determined from high-accuracy archeomagnetic dating" by S. Arrighi et al., Geophys. Res. Lett., 32(23), L23306, doi:10.1029/2005GL022590, 2005.

Speranza, F., Branca, S., Coltelli, M., Caracciolo, F. D., and Vigliotti, L.: How accurate is "paleomagnetic dating"'? New evidence from historical lavas from Mount Etna, J. Geophys. Res., 111, B12S33, doi:10.1029/2006JB004496, 2006.

Speranza, F., Pompilio, M., Caracciolo, F. D., and Sagnotti, L.: Holocene eruptive history of the Stromboli volcano: Contraints from paleomagnetic dating, J. Geophys. Res., 113, B09101, doi:10.1029/2007JB005139, 2008.

Tanguy, J.-C., Bucur, I., and Thompson, J.: Geomagnetic secular variation in Sicily and revised ages of Historic lavas from Mount Etna, Nature, 318, 453-455, 1985.

Tanguy, J.-C., Goff, M. L., Principe, C., Arrighi, S., Chillemi, V., Paiotti, A., Delfa, S. L., and Patanè, G.: Archeomagnetic dating of Mediterranean volcanics of the last 2100 years: Validity and limits, Earth Planet. Sc. Lett., 211, 111-124, 2003.

Vezzoli, L., Principe, C., Malfatti, J., Arrighi, S., Tanguy, J.-C., and Goff, M. L.: Modes and times of caldera resurgence: The $<10 \mathrm{ka}$ evolution of Ischia Caldera, Italy, from high-precision archeomagnetic dating, J. Volcanol. Geotherm. Res., 186, 305319, 2009

Zanella, E.: Paleomagnetism of Pleistocene volcanic rocks from Pantelleria Island (Sicily Channel), Italy, Phys. Earth Planet. Int., 108, 291-303, 1998. 